Jun Zhang

Michael A. Williams

Daniele Rigamonti

\title{
Genetics of human hydrocephalus
}

Abstract Human hydrocephalus is a common medical condition that is characterized by abnormalities in the flow or resorption of cerebrospinal fluid (CSF), resulting in ventricular dilatation. Human hydrocephalus can be classified into two clinical forms, congenital and acquired. Hydrocephalus is one of the complex and multifactorial neurological disorders.

A growing body of evidence indicates that genetic factors play a major role in the pathogenesis of hydrocephalus. An understanding of the genetic components and mechanism of this complex disorder may offer us significant insights into the molecular etiology of impaired brain development and an accumulation of the cerebrospinal fluid in cerebral compartments during the pathogenesis of hydrocephalus. Genetic studies in animal models have started to open the way for understanding the underlying pathology of hydrocephalus. At least 43 mutants/loci linked to hereditary hydrocephalus have been identified in animal models and humans. To date, 9 genes associated with hydrocephalus have been identified in animal models. In contrast, only one such gene has been identified in humans. Most of the known hydrocephalus gene products are the important cytokines, growth factors or related molecules in the cellular signal pathways during early brain development. The current molecular genetic evidence from animal models indicates that in the early development stage, impaired and abnormal brain development caused by abnormal cellular signaling and functioning, all these cellular and developmental events would eventually lead to the congenital hydrocephalus.

Owing to our very primitive knowledge of the genetics and molecular pathogenesis of human hydrocephalus, it is difficult to evaluate whether data gained from animal models can be extrapolated to humans. Initiation of a large population genetics study in humans will certainly provide invaluable information about the molecular and cellular etiology and the developmental mechanisms of human hydrocephalus.

This review summarizes the recent findings on this issue among human and animal models, especially with reference to the molecular genetics, pathological, physiological and cellular studies, and identifies future research directions.

Key words hydrocephalus . congenital $\cdot$ acquired ·

genetic of $\cdot$ multifactorial disorder 


\section{Introduction}

Human hydrocephalus is a significant medical condition with an estimated incidence of 1 in 1500 births [1]. Hydrocephalus is characterized by abnormalities in the flow or resorption of cerebrospinal fluid (CSF), resulting in ventricular dilatation. However, hydrocephalus is far more complicated than a simple disorder of CSF circulation [2]. Although commonly considered a single disorder, human hydrocephalus is a collection of a heterogeneous complex and multifactorial disorders [3]. Genetic factors are involved in the pathogenesis of hydrocephalus [4-6]. For the purposes of this review, we categorize hydrocephalus as congenital, which is present at birth and often associated with developmental defects; and acquired, which occurs after development of the brain and ventricles [7-12].

The development and progression of congenital hydrocephalus is a dynamic process that is not yet well understood. It is thought that it may develop at an important and specific embryonic time period of neural stem cell proliferation and differentiation in the brain $[13,14]$. Congenital hydrocephalus may occur alone (non-syndromic) or as part of a syndrome with other anomalies (syndromic) $[15,16]$. In syndromic forms, it is hard to define the defective gene because of the association with other anomalies. We will mainly focus on isolated forms of hydrocephalus. In genetic terms, the isolated (non-syndromic) form of hydrocephalus is a primary and major phenotype caused by a specific faulty gene.

It is estimated that about $40 \%$ of hydrocephalus cases have a possible genetic etiology [10]. In humans, $\mathrm{X}$-linked hydrocephalus (HSAS1, OMIM) comprises approximately $5-15 \%$ of the congenital cases with a genetic cause [10,17-20]. Although there is strong evidence for genetic causes, only one hydrocephalus gene (X-linked) has been identified in humans.

Besides genetic factors, many other factors influence the development of congenital hydrocephalus, such as congenital malformations, intracerebral hemorrhage, maternal alcohol use [21, 22], infection [6, 23-25], and $\mathrm{X}$-ray radiation during pregnancy $[26,27]$.

\section{Genetics in hydrocephalus}

Congenital hydrocephalus is the more common of the two forms of hydrocephalus, and is probably the consequence of abnormal brain development and perturbed cellular function, which emphasizes the important roles that congenital hydrocephalus genes play during brain development. In general, the recurrence risk for congenital hydrocephalus excluding $\mathrm{X}$-linked hydrocephalus is low. Empiric risk rates range from $<1 \%$ to $4 \%$ [28-30], indicating the rarity of autosomal recessive congenital hydrocephalus $[10,20,31,32]$. However, multiple human kindreds with congenital hydrocephalus have been reported $[10,15,20,32-43]$. The loci or genes for human autosomal recessive congenital hydrocephalus have not yet been identified, but there is at least one locus for this trait. Furthermore, like animal models, since there is heterogeneity among clinical phenotypes, there may be more genetic loci in human autosomal recessive congenital hydrocephalus.

One kindred was reported in which congenital hydrocephalus was transmitted in an autosomal dominant fashion. This condition was associated with aqueductal stenosis but was not associated with mental retardation or pyramidal tract dysfunction. The lack of mental retardation and pyramidal tract dysfunction was in contrast to X-linked or recessive congenital hydrocephalus with stenosis of the aqueduct of Sylvius (HSAS), in which these abnormalities are commonly seen [44]. Another study identified a kindred with a microdeletion of 8q12.2-q21.2 which subsequently developed hydrocephalus. This trait was also transmitted in an autosomal dominant fashion [45]. Molecular genetic studies have revealed that the responsible gene for $\mathrm{X}$-linked human congenital hydrocephalus is at Xq28 encoding for L1CAM (L1 protein) [46]. The mutations are distributed over the functional protein domains. The exact mechanisms by which these mutations cause a loss of L1 protein function are still under investigation.

Another form of this disorder, acquired or adultonset hydrocephalus is mostly sporadic and characterized by ventricular enlargement in the absence of significant elevations of intracranial pressure; therefore this form is termed normal pressure hydrocephalus (NPH). Definite changes in CSF flow, resorption, and associated dynamics have been found in NPH patients, and these changes may represent a pathogenic mechanism or a secondary phenomenon [47]. Adult-onset hydrocephalus may develop either as a result of decompensation of a "compensated" congenital hydrocephalus, or it may arise de novo in adult life secondary to an acquired disturbance of normal CSF dynamics. The latter may be due to lateonset aqueductal stenosis or disruption of normal CSF absorptive pathways [11, 48]. Acquired (adultonset, or NPH) form of inherited hydrocephalus is very rare. Recently, an X-linked adult-onset NPH [49] and a form of familial NPH that is transmitted in autosomal dominant fashion [50] have been reported, but detailed genetic linkage studies have not been carried out yet. The genetic etiology of this form is therefore totally unknown. 
Hydrocephalus has been observed in many mammals [51-59]. Animal hydrocephalus models have many histopathological similarities to humans and can be used to understand the genetics and pathogenesis of brain damage [59-64]. It has been well documented in the animal models that in the majority of cases, congenital hydrocephalus is a genetic disease. Furthermore, many congenital hydrocephalus loci have been mapped and identified in the animal models.

Hydrocephalic Texas strain (HTX) rat model of inherited congenital hydrocephalus is characterized by onset in late gestation, a complex mode of inheritance, and ventricular dilatation associated with abnormalities in the cerebral aqueduct and subcommissural organ (SCO), a structure that is important for the patency of the aqueduct of Sylvius and normal CSF flow in the brain. Quantitative trait locus (QTL) genetic mapping has been performed from the progeny of a backcross of HTX rat with the non-hydrocephalic Fischer F344 strain. The disease has been linked with loci on chromosome (Chr) 9 (peak markers D9Rat2), 10 (between markers D10Rat136 and D10Rat135), 11 (peak markers D11Arb2 and D11Rat46) and 17 (peak markers D17mit4 and D17Rat154) respectively. The severity of hydrocephalus in HTX rat seems to be influenced by different genetic loci [65-68]. Another study suggested that the HTX strain is homozygous carrier of an autosomal recessive hydrocephalus gene with incomplete penetrance [69]. The genetics of another hydrocephalus inbred strain, Wistar-Lewis rats (LEW/Jms) which demonstrate inherited congenital hydrocephalus, is less clear with possible traits as an autosomal recessive [70] or semidominant or multigenic (possible QTL) with a possible locus on sex chromosomes [71], but none of the loci has been localized.

In mouse models, three QTL loci associated with congenital hydrocephalus have been identified and labeled as Vent8a, Vent4b, and Vent7c. As a major QTL controlling variance in ventricular size, Vent8a is located on Chr 8 (near the markers D8Mit94 and D8Mit189). The Other two loci, Vent4b and Vent7c, show strong epistatic interactions affecting ventricular size in the developing embryo. Vent $4 \mathrm{~b}$ is located on Chr 4 (near D4Mit237 and D4Mit214), and Vent7c is located on Chr 7 (between D7Mit178 and D7Mit191) [72].

The autosomal recessive congenital hydrocephalus-1 (hy1) mouse has been characterized phenotypically by a dome-shaped head that is sometimes seen at birth or develops during the first 2 weeks. Internally, dilatation of the entire ventricular system is observed [73,74]. A more severe phenotypic form, hydrocephalus-2 (hy2) mouse $[75,76]$, and an obstructive hydrocephalus (oh) mouse with commu- nicating hydrocephalus and secondary aqueductal stenosis have also been described [77, 78]. Unfortunately subsequent efforts to identify genetic loci have not been done on these non-inbred mouse strains.

In mouse targeted insertional mutagenesis, the accidental insertion of a transgene into a crucial genomic locus could yield important information, which has happened twice in hydrocephalus genetic studies. The transgenic mouse line OVE459 demonstrates autosomal recessive congenital hydrocephalus. This is caused by a Bdnf transgene-induced insertional mutation on a single locus on mouse Chromosome 8 (near marker D8Mit152). The OVE459 insertion locus is overlapped with that of autosomal recessive hydrocephalus-3 (hy3) mouse that phenotypically shows lethal communicating hydrocephalus with perinatal onset $[79,80]$. The transgene insertion resulted as a rearrangement of Hydin exons in OVE459 mice. Subsequently, a single CG base-pair deletion in exon 15 of Hydin was also discovered in hy3 mice carrying the spontaneous hy3 mutant allele [81, 82].

In another targeted insertional mutagenesis resulting in congenital hydrocephalus, the CYP2J2 transgene interferes with the expression of a brainspecific isoform of the regulatory factor X4 (RFX4), which belongs to the winged helix transcription factor family. This brain specific isoform is called variant transcript 3 or RFX4_v3 and is crucial for normal brain development as well as for the genesis of the SCO. Loss of a single allele prevents formation of the SCO and leads to an autosomal dominant congenital hydrocephalus. This obstructive hydrocephalus appeared to be secondary to failure of development of the SCO [83].

The autosomal recessive congenital hydrocephalus (ch) mouse was reported decades ago [79]. Recently this mouse has been shown to have a mutation on another winged helix/forkhead transcription factor gene, Foxc1 (Mf1) on mouse Chromosome 13 [84, 85]. There is a recent report of 6 children with hydrocephalus from 3 different families with subtelomeric deletions from chromosome $6 \mathrm{p}$. Three forkhead genes within this region (FOXF1 and FOXQ1) or proximal to it (FOXC1) were evaluated as potential candidate disease genes but no disease causing mutations were identified [86].

The autosomal recessive hydrocephalus with hop gait (hyh) mouse exhibits dramatic dilation of the ventricles at birth and invariably develops hopping gait. The hyh mouse shows a markedly small cerebral cortex at birth and dies postnatally from progressive enlargement of the ventricular system. The small cortex in hyh mouse reflects altered development of the neuronal cells. In this mouse, it is postulated that neural progenitor cells withdraw prematurely from the cell cycle, producing more early-born, deep-layer 
cerebral cortical neurons but depleting the cortical progenitor pool, and creating a small cortex. Genetic linkage analysis localized the hyh locus between markers D7Mit75 and D7Mit56 on mouse Chr 7. Later, the hyh gene was identified as $\alpha$-SNAP (soluble NSF attachment protein $\alpha$ ) [87]. Homozygous mutant mice harbor a missense mutation M105I in a conserved residue in one of the $\alpha$-helical domains. The hyh mutant was not a null allele and is expressed; however, the mutant protein is $40 \%$ less abundant in hyh mice.

The autosomal recessive hemorrhagic hydrocephalus (hhy) homozygous mutant mouse has dilated lateral ventricles and a patent aqueduct, with no histological abnormalities either in the subarachnoid space or in the choroid plexus. Multiple hemorrhages in the meninges and throughout the brain parenchyma can be observed in the advanced stages of hydrocephalus. The hhy locus has been localized on mouse Chr 12 [88].

Recently, several new congenital hydrocephalus models have emerged in zebra fish mutagenesis screening. These models have been shown to have the defects in embryogenesis and early development leading to enlarged brain ventricles. However, genetic loci for these models have not been identified yet [89, 90].

Genetic studies in animal models have started to open the way for understanding the underlying pathology of hydrocephalus. In contrast to research with animal models, human hydrocephalus genetic research has lagged far behind. To date, at least 43 mutants of hydrocephalus have been described, and 10 congenital hydrocephalus genes have been identified. Among them, only one hydrocephalus gene has been identified in humans (see Table 1).

\section{Developmental, physiological and anatomical pathology of hydrocephalus}

The neuropathology of hydrocephalus has been adequately elucidated. Cerebral ventricle dilatation secondary to disturbed CSF flow has been observed as an inheritable trait in a variety of laboratory animals (as well as in humans). In most cases, defective development of the cerebral aqueduct or the subarachnoid space has been observed [61]. Affected individuals may have severe developmental delay and radiographic findings of hydrocephalus [91].

The morphological and developmental changes in the ventricular system have been well studied in three major rat models of congenital hydrocephalus: 6-aminonicotinamide (6-AN)-induced, LEW/Jms and HTX mutant rats. Comparative morphological stud- ies revealed that 6-AN-induced hydrocephalus was comparable to the Dandy-Walker syndrome. The LEW/Jms and HTX mutant models were identical with regard to the form of presentation and progression of hydrocephalus in the postnatal period; but the pathogenesis of these two conditions in the fetal period was different. The LEW/Jms rats showed primary congenital aqueductal stenosis in early prenatal life and the hydrocephalic state appeared before pulmonary maturation was completed. However, although the model has been considered to be of congenital communicating hydrocephalus [64], the HTX fetuses demonstrated secondary closure of the aqueduct in the perinatal period. This secondary closure of the aqueduct in HTX rats is believed to be due to retrograde degeneration of the thalamus caused by apoptotic cell death [92, 93] and failure in cell proliferation [94, 95]. The HTX rat also shows a reduction in the secretory cells of the SCO. Regarding the role of the SCO in hydrocephalus pathogenesis, serial brain sections through aqueduct regions containing the SCO from HTX rats, in comparison with normal Fischer F344 strain, have been studied and found that reduced SCO glycoprotein immunoreactivity precedes both aqueduct closure and expansion of the lateral ventricles in the HTX rate (as it's redundant) [96, 97].

Although some studies have addressed the activation of macrophages and microglia (the resident mononuclear phagocytes of the brain) within the brain in animal hydrocephalus models, little is known of their state of activation or regional distribution in human congenital hydrocephalus. In one experiment, brain tissue samples of 10 human fetal cases with hydrocephalus and 10 non-hydrocephalic controls were stained immunohistochemically with antibodies directed against MHC class II and CD68 antigens, and lectin histochemistry was done with tomato lectin. Hydrocephalus cases showed focal collections of CD68 and tomato lectin-positive macrophages along the ependymal lining of the lateral ventricles, particularly within the occipital horn. By comparison, brain tissue samples from controls showed few or no ependymal or supraependymal macrophages and the few macrophages that were present were not as intensely immunoreactive as in the hydrocephalus cases. The macrophage response detected at the ependymal lining of the ventricles and within the periventricular area in hydrocephalus may be related both to the severity of hydrocephalus and the age of the fetus [98]. Microglia that are normally interspersed throughout the intermediate zone and circumscribing the basal ganglia were within normal confines in all cases examined. Unexpectedly, hydrocephalic cases also showed focal regions of hypovascularization or alterations in the structure and 
Table 1 Summary of current known loci (or mutants) of hydrocephalus in vertebrates

\begin{tabular}{|c|c|c|c|c|c|c|c|c|}
\hline Species & Strain & Clinical form & Trait* & Locus & Chromosome & Human syntenic region & Human Gene & References \\
\hline Human & & C & $A R$ & Unknown & unknown & & & $10,15,27,32-43$ \\
\hline Human & & C & $A D$ & Unknown & $8 q 12.2-21.2$ or unknown & & & 44,45 \\
\hline Human & & AO & $A D$ & NPH & unknown & & & 50 \\
\hline Human & & $\mathrm{C}$ & X-linked & L1cam & $x$ & $\mathrm{x}$ & L1CAM & 46 \\
\hline Human & & AO & X-linked & Unknown & $x$ & $x$ & & 49 \\
\hline Rat & HTX & $\mathrm{C}$ & QTL & D9Rat2 & $9 q 38$ & $5 q 21.1,18 p 11.22-31$ & & $65-68$ \\
\hline Rat & HTX & C & QTL & D10Rat136, D10Rat135 & $10 q 32.1-10 q 32.3$ & $17 q 21.3-q 25.3$ & & $65-68$ \\
\hline Rat & HTX & C & QTL & D11Arb2, D11Rat46 & $11 \mathrm{q} 23$ & $3 q 27-28,22 q 11.21,10 p 12.2$ & & $65-68$ \\
\hline Rat & HTX & C & QTL & D17Mit4, D17Rat154 & $17 q 12.1$ & $1 \mathrm{q} 43,10 \mathrm{p} 11.21-\mathrm{p} 13$ & & $65-68$ \\
\hline Rat & $\mathrm{LEW} / \mathrm{Jms}$ & C & $A R,(Q T L)$ & unknown & unknown & & & 70,71 \\
\hline Mouse & C57BL/6J & $\mathrm{C}$ & QTL & Vent8a & 8 & $8 p 11-23,13 q 11-34$ & & 72 \\
\hline Mouse & C57BL/6J & C & QTL & Vent $4 b$ & 4 & $6 p, 9$ & & 72 \\
\hline Mouse & $\mathrm{C} 57 \mathrm{BL} / 6 \mathrm{~J}$ & C & QTL & Vent7c & 7 & $19 q 10-13$ & & 72 \\
\hline Mouse & hy1 & C & $A R$ & unknown & unknown & & & 73,74 \\
\hline Mouse & hy2 & C & $A R$ & unknown & unknown & & & 75,76 \\
\hline Mouse & hy3 & $\mathrm{C}$ & AR & Hydin & 8 & $16 q 22.2$ & HYDIN & $79-82$ \\
\hline Mouse & C57BL/10J & C & AR & hyh & 7 & $19 q 13.3$ & a-SNAP & 87,100 \\
\hline Mouse & C57BL6/J & C & $A D$ & Rfx4 & 10 & $12 q 24$ & RFX4 & 83 \\
\hline Mouse & $\mathrm{BALB} / \mathrm{CHeA}$ & C & $A R$ & hhy & 12 & $14 q 32$ & & 88 \\
\hline Mouse & ch & C & $A R$ & Mf1 & 13 & $6 p 25$ & FREAC-3 & 84 \\
\hline Mouse & STOCK tb & C & $A R$ & oh & unknown & & & 77,78 \\
\hline Mouse & $\mathrm{C} 57 \mathrm{BL} / 6^{*} \mathrm{CBA} / \mathrm{J}$ & C & $A R$ & Mdnah5 & 15 & $5 p 15.2$ & DNAH5 & 106 \\
\hline Mouse & C57BL/CBA & C & $A D$ & $0 t \times 2$ & 14 & $14 q 21-q 22$ & 0TX2 & 122 \\
\hline Mouse & 129P2/0laHsd & C & $A R$ & Msx1 & 5 & $4 p 16.3-p 16.1$ & MSX1 & 107,108 \\
\hline Mouse & C57BL/6 & C & $A R$ & Socs7 & 11 & $17 q 12$ & SOCS7 & 118 \\
\hline Mouse & C57BL/6J & C & $A R$ & Nmhc-b & 11 & $17 q 13$ & MYH10 & 121 \\
\hline Zebrafish & $\mathrm{m} 404 / \mathrm{m} 491$ & $\mathrm{C}$ & AR & apo & unknown & & & 89,90 \\
\hline Zebrafish & $\mathrm{m} 409 / \mathrm{m} 432$ & C & AR & cudak & unknown & & & 89,90 \\
\hline Zebrafish & m691 & $\mathrm{C}$ & AR & eagle & unknown & & & 89,90 \\
\hline Zebrafish & m591 & C & $A R$ & endeavor & unknown & & & 89,90 \\
\hline Zebrafish & m584 & C & $A R$ & enterprise & unknown & & & 89,90 \\
\hline Zebrafish & m492/m510 & $\mathrm{C}$ & AR & galileo & unknown & & & 89,90 \\
\hline Zebrafish & $\mathrm{m} 445 / \mathrm{m} 585 / \mathrm{m} 700$ & C & AR & gumowy & unknown & & & 89,90 \\
\hline Zebrafish & m727 & C & $A R$ & hubble & unknown & & & 89,90 \\
\hline Zebrafish & $\mathrm{m} 221 / \mathrm{m} 470 / \mathrm{m} 680$ & C & $A R$ & interrail & unknown & & & 89,90 \\
\hline Zebrafish & $\mathrm{m} 733$ & C & $A R$ & kepler & unknown & & & 89,90 \\
\hline Zebrafish & $\mathrm{m} 728$ & $\mathrm{C}$ & AR & neil & unknown & & & 89,90 \\
\hline Zebrafish & m481 & C & AR & pan twardowski & unknown & & & 89,90 \\
\hline Zebrafish & $\mathrm{m} 172 / \mathrm{m} 476$ & C & $A R$ & uchu hikoushi & unknown & & & 89,90 \\
\hline Zebrafish & $\mathrm{m} 766$ & C & $A R$ & voyager & unknown & & & 89,90 \\
\hline Zebrafish & m331 & C & $A R$ & viking & unknown & & & 89,90 \\
\hline Zebrafish & $\mathrm{m} 479 / \mathrm{m} 627$ & C & $A R$ & yura & unknown & & & 89,90 \\
\hline Zebrafish & $\mathrm{m} 111 / \mathrm{m} 307 / \mathrm{m} 512 / \mathrm{m}$ & $\mathrm{m} 97 \mathrm{C}$ & $A R$ & zezem & unknown & & & 89,90 \\
\hline
\end{tabular}

* Genetic trait, AR: autosomal recessive, AD:autosomal dominant, QTL: Quantitative trait locus, ${ }^{* *}$ clinicalform, C: congenital, A0: Adut-Onset

orientation of capillaries within periventricular areas, compared with controls [98].

In summary, the pathological studies of hydrocephalus clearly indicate that impaired and abnormal brain development in the early development stage caused by altered neural cell fate and perturbed regulation of cellular proliferation and apoptosis. The abnormal brain development subsequently leads to the accumulation of the CSF in cerebral cavities. All these cellular and developmental events eventually lead to the congenital hydrocephalus accompanied by possible secondary inflammatory reaction and neurovascular pathogenesis.

\section{The molecular and cellular etiology of hydrocephalus}

One of the possible mechanisms leading to the pathogenesis of hydrocephalus is the disruption of neural cell membrane proteins that play an important function during brain development. The L1 protein coded by human X-linked hydrocephalus gene is a member of the immunoglobulin superfamily of neural cell adhesion molecules that is expressed in neurons and Schwann cells, and seems to be essential for the brain development and function. Hirschsprung's disease 
(HSCR) is characterized by the absence of ganglion cells and the presence of hypertrophic nerve trunks in the distal bowel. There have been several reports of patients with X-linked hydrocephalus and HSCR with a mutation in the L1CAM gene. Therefore, decreased L1CAM may also be a modifying factor in the development of HSCR [99].

The gene carrying the mutation for autosomal recessive hydrocephalus in the hyh mouse codes $\alpha$ SNAP protein. $\alpha$-SNAP is essential for apical protein localization and cell fate determination in neuroepithelial cells [100]. $\alpha$-SNAP plays a key role in a wide variety of membrane fusion events in eukaryotic cells. Membrane fusion is required for two main cellular functions: 1) the transport of molecules to distinct inter- and intracellular compartments and thereby maintenance of the functional and structural organization of eukaryotic cells; 2) the intercellular communication such as the regulated exocytosis (secretion) of neurotransmitters by neuronal cell, which occurs temporally and spatially as the precise sequential regulation events at the plasma membrane during the early brain development [87]. In the hyh mouse model, altered neural cell fate is also accompanied by abnormal localization of many apical proteins implicated in regulation of neural cell fate, including E-cadherin, beta-catenin, atypical protein kinase C (aPKC), inactivation-no-afterpotential D-like (INADL), SNAP receptor (SNARE), and vesicle-associated membrane protein-7 (VAMP-7) [100]. Furthermore, disturbed astrocyte metabolism in the early brain development in the kaolin-induced rat model of hydrocephalus has also been reported [101].

Hydrocephalus may also be caused by a malfunction of the ependymal cells [102-105]. Within the neonatal brain of the mouse, the hy 3 protein (hydin) is confined to the ciliated ependymal cell layer lining the lateral, third and fourth ventricles. Hydin is not closely related to any previously known protein, with the exception of a 314 amino acid domain with homology to caldesmon, an actin-binding protein, suggesting that hydin interacts with the cytoskeleton $[81,82]$. The protein of axonemal heavy chain 5 gene (Mdnah5), dynein is also specifically expressed in ependymal cells, and is essential for ultra structural and functional integrity of ependymal cilia. In Mdnah5-mutant mice, lack of ependymal flow causes closure of the aqueduct and subsequent formation of triventricular hydrocephalus during early postnatal brain development. The higher incidence of aqueductal stenosis and hydrocephalus formation in patients with ciliary defects proves the relevance of this novel mechanism in humans [106].

Hydrocephalus may be caused by malfunction of mesenchymal cells. In mice, Msx 1 is a regulatory gene involved in epithelio-mesenchymal interactions in limb formation and organogenesis. In the embryonic brain, the Msxl gene is expressed along the dorsal midline. The most important features observed in homozygous Msx1 mutants were the absence or malformation of the posterior commissure (PC) and of the SCO, the collapse of the cerebral aqueduct, and the development of hydrocephalus. The heterozygous mutants developed an abnormal PC and smaller SCO, as revealed by specific antibodies against SCO secretory glycoproteins. About one third of the heterozygous mutants also developed hydrocephalus; therefore the phenotype may be determined by the Msxl gene dosage during a specific developmental period [107, 108]. In the autosomal recessive congenital hydrocephalus (ch) mouse model, a truncated protein lacking the DNA-binding domain of the forkhead/winged helix gene, Mf1, was generated. Mesenchymal cells from Mf1lacZ embryos differentiate poorly into cartilage in micromass culture and do not respond to added bone morphogenetic protein 2 (BMP2) and transforming growth factor-beta 1 (TGFB1). The differentiation of arachnoid cells in meninges of the mutant mice is also abnormal. The levels of developmental growth factors such as TGFB1 and BMP2 are dramatically increased in the ch mouse, and it is possible that phenotypic hydrocephalus of Mf1 mouse is due to the secondary effect of these elevated growth factors. Corresponding to studies in the ch mouse, human patients with deletions in the region containing human Mf1 homolog FREAC3 were found to develop multiple developmental disorders, including hydrocephalus [84]. Another winged helix transcription factor causing congenital hydrocephalus when mutated, RFX4_v3 transcript, is dynamically expressed in the developing brain from the neural plate stages. The RFX proteins belong to the wingedhelix subfamily of helix-turn-helix transcription factors, and bind to 'X-boxes' in target DNA sequences and regulate expression of the downstream target genes [83]. Disruption of both RFX4_v3 alleles by insertional mutagenesis severely alters early brain morphogenesis, reduces Msx2 expression, and causes a deficiency in WNT signaling [83]. This may suggest that RFX4_v3 is probably upstream of Mf1 in the signaling pathway during early brain development.

Hydrocephalus may be caused by perturbation of growth factor signaling [109, 110]. Developmental abnormalities in congenital hydrocephalus provide the clues for the perturbation of major signaling pathways in the development [111]. TGFB is an important cytokine and growth-signaling molecule in the brain. In mouse models, severe hydrocephalus has been observed in transgenic mouse overexpression of TGFB1 in astrocytes [112, 113]. In the HTX rat, increased level of TGFB3 may contribute to the development of hydrocephalus [114]. In mouse models, 
fibroblast growth factor-2 (FGF-2) seems to play a predominant role in the proliferation of neuronal precursors and in neuronal differentiation in the developing cerebral cortex even at relatively late stages of brain neurogenesis. Administration of FGF-2 to embryonic brain induces hydrocephalic brain morphology and aberrant differentiation of neurons in the postnatal cerebral cortex [110]. IGF binding protein-1 (IGFBP-1) modulates the cellular action of insulin-like growth factors (IGFs), some of which are expressed in the fetal brain. Hydrocephalus has been observed in mouse models that overexpress liver-specific IGFBP-1 during fetal life. The hepatic over-expression of IGFBP-1 may have endocrine effects on brain development and induction of congenital hydrocephalus [115]. Other studies have shown that up-regulation of certain growth factors in the brain could lead to altered brain fluid dynamics [116, 117]. SOCS7 is a member of the suppressor of cytokine signaling (SOCS) protein family. SOCS proteins have a similar structure: an $\mathrm{N}$-terminal domain of variable length, a central Src homology-2 domain, and a C-terminal SOCS box. Biochemical and genetic studies have revealed that SOCS family members play an important role in the termination of cytokine and growth factor signaling. Homozygous Socs7 mutant mice were born in expected numbers, were fertile, and did not exhibit defects in hematopoiesis or circulating glucose or insulin concentrations. Strikingly however, these homozygous Socs7 mice were $7-10 \%$ smaller than their wild-type littermates, and within 15 weeks of age approximately $50 \%$ of the homozygous Socs7 mice died as a result of hydrocephalus. In situ hybridization studies in normal mice have revealed that Socs7 is prominently expressed in the brain, suggesting that SOCS7 plays an important functional role in early brain development [118]. We can therefore hypothesize that loss of SOCS7 function will lead to increased expression of cytokines resulting in developmental abnormalities and congenital hydrocephalus due to its inhibitory role in cytokine signaling.

Hydrocephalus may also be caused by the disruption of extracellular matrix (ECM). In the TGFB1 over-expression mouse model, the changing expressions of a remodeling protein - matrix metalloproteinase-9 (MMP-9) and its specific inhibitor- tissue inhibitor of metalloproteinases-1 (TIMP-1) were also found to be important factors in the spontaneous development of hydrocephalus by altering the ECM environment [119]. Furthermore, increased expression of cytokines such as TGFB1 might also reciprocally play an important role by disrupting the vascular ECM remodeling, promoting hemorrhages, and altering the re-absorption of CSF [120]. In another mouse model, ablation of the nonmuscle myosin heavy chain II-B (NMHC-B) results in severe hydro- cephalus with enlargement of the lateral and third ventricles. These defects may be caused by abnormalities in the cell adhesive properties of neuroepithelial cells and suggest that NMHC-B is essential for both early and late developmental processes in the mammalian brain [121].

Hydrocephalus may also be caused by the disruption of major early brain developmental patterning molecules. Autosomal dominant hydrocephalus in Otx2 mutation mice is characterized by eminent dilatation of lateral ventricles and a ballooned cerebrum. Histopathology shows edematous change of the periventricular white matter, suggesting that Otx2 functions as a brain developmental organizer, and a disruption of this gene is a likely cause of hydrocephalus [122].

In conclusion, many genetic loci of hydrocephalus have been defined in animal models, which is building a foundation for better understanding of molecular etiology of hydrocephalus; however, genetic research of hydrocephalus in humans is limited. The histopathological similarities of animal models can be used to understand the genetics and pathogenesis of human hydrocephalus. For example, the histopathological and morphological appearance of hydrocephalic HTX rats is demonstrated in Fig. 1, in which hydrophilic HTX rat exhibits large cerebral ventricles, a progressively-thinned cortical mantle, and stretched internal capsule fibers[123]. Review of the molecular etiologies shows a very diverse set of pathogenetic mechanisms. Perturbation of almost any molecule that plays a crucial role in early brain development, and sequentially regulation of dynamics of cerebrospinal fluid, could lead to the pathogenesis of congenital hydrocephalus. The 10 known hydrocephalus genes mostly code for important cytokines, growth factors, or related molecules in the cellular signal pathways during early brain development.

\section{Future prospects}

It is essential to recognize that molecular genetics is the only current scientific approach that can be used to study hydrocephalus in which the usual concern about whether an observed phenomenon is a consequence or a cause is completely addressed.

Despite our knowledge of the genetics of hydrocephalus in animal models, we have very limited knowledge about the genetic and molecular mechanisms that cause human hydrocephalus. Without this knowledge, it is impossible to say whether the pathogenesis of human hydrocephalus is comparable to that seen in animal models, and impractical to extrapolate data gained from animal models to humans. In order to better understand human 


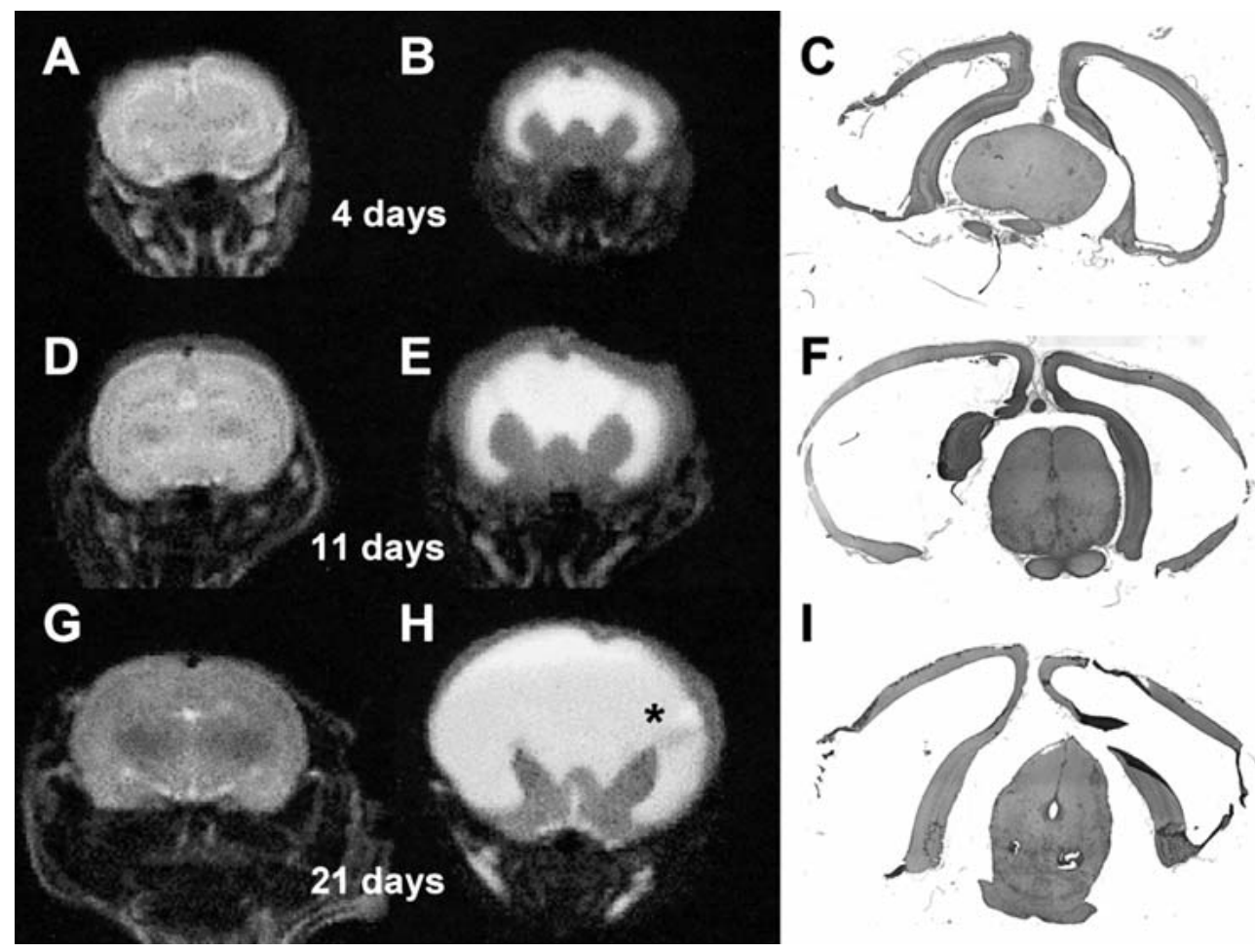

Fig. 1 Comparison of rat brain morphology by MRI and histology at 4, 11 and 21 days of age in non-hydrocephalic and hydrocephalic HTX rats. T2-weighted MRI scans of coronal sections from a non-hydrocephalic HTX rat at the level of the thalamus at 4, 11 and 21 days (A, D, G) shows small ventricular and subarachnoid spaces compared to an age-matched HTX littermate $(\mathbf{B}, \mathbf{E}, \mathbf{H})$ that exhibits large cerebral ventricles, a progressively-thinned cortical mantle, and stretched internal capsule fibers $\left(^{*}\right)$. Congenital closure of the cerebral aqueduct becomes life-threatening by 21 days of age. Histological sections $(\mathbf{C}, \mathbf{F}, \mathbf{I})$ at the level of the midbrain at the same ages demonstrate extreme thinning of the cortical mantle. MRI images are modified from Jones et al (2000) [123] with permission by Maney Publishing; histological samples are from the doctoral thesis of Janet M. Miller, PhD

hydrocephalus and to develop more appropriate translational research, it will be necessary to conduct large-scale genetic studies of human hydrocephalus. If, and when, more heritable forms of human hydrocephalus are identified, and underlying genes and their functions are characterized, then this knowledge could be used to improve patient care in a variety of different ways such as prenatal diagnosis and new potential therapeutic approaches. Possible new mechanisms other than altered CSF circulation and resorption, if uncovered via the genetic research, may also help explain why patients with hydrocephalus may experience symptomatic progression despite functioning shunts.

Efforts to identify genetic variants associated with susceptibility to genetic diseases rely on three major approaches: pedigree and sib-pair linkage analysis and population association studies. The differences among these study designs reflect their derivation from biological versus epidemiological traits. Like most common diseases, it would be very difficult to identify and recruit large pedigrees in hydrocephalus that show hereditary transmission of the condition. Therefore, the last two approaches, sib-pair linkage analysis and population association studies, are the best options for the genetic study on this disease. For any study, but particularly in the case of genetic mapping for a common disease, a large sample size is crucial in achieving statistical significance. Recent advances in the genomics and statistical methodology in genetic mapping will certainly help in making wellpowered studies more feasible, by reducing the number of genetic markers or workload required for these studies. For example, since many genes and loci response for hydrocephalus in animal models have been mapped, candidate genes approach will certainly be the very first choice to test the collected human hydrocephalus population for linkage and association analysis.

In collaboration with the Hydrocephalus Association (HA), our group has initiated a genetic study of human hydrocephalus. As part of a prospective study that has been approved by the Johns Hopkins Institutional Review Board, we are collecting blood samples from both congenital and acquired NPH hydrocephalus patients. The objectives of this study are to identify the genetic loci responsible for the development of hydrocephalus, to examine the relationship between genotype and phenotype and to define the functions of these genes during early 
development. This is the first large-scale research study of its kind and information gained from this study will undoubtedly provide invaluable information concerning the developmental mechanisms of this disease in humans. Such knowledge will hopefully lead to the more reasonable treatment schemes, the better diagnostic tools, and the more effective therapeutic modalities.
Acknowledgements We thank Siddharth Kharkar and John W. Shuck at Johns Hopkins University Hydrocephalus Research Center for their kind help and review of this manuscript. We thank and acknowledge James P. (Pat) McAllister II, PhD and Janet M. Miller, $\mathrm{PhD}$ at the Department of Neurological Surgery, Wayne State University School of Medicine for providing Figure 1. We also thank and acknowledge Maney Publishing, as the copyright holder of the original publication for MRI images in Fig. 1, for their permission of our reproduction in this manuscript.

\section{References}

1. Schurr PH, McLaurin RL, Ingraham FD (1953) Experimental studies on the circulation of the cerebrospinal fluid and methods of producing communicating hydrocephalus in the dog. J Neurosurg 10:515-525

2. Czosnyka M, Czosnyka Z, Schmidt EA, et al. (2003) Cerebrospinal fluid production. J Neurosurg 99:206-207 author reply 207

3. Willems PJ (1988) Heterogeneity in familial hydrocephalus. Am J Med Genet 31:471-473

4. Price JR, Horne BM (1968) Family history indicating hereditary factors in hydrocephalus. Ment Retard 6:4041

5. Tipton RE (1971) Familial hydrocephalus. Birth Defects Orig Artic Ser 7:231

6. Stoll C, Alembik Y, Dott B, et al. (1992) An epidemiologic study of environmental and genetic factors in congenital hydrocephalus. Eur J Epidemiol 8:797-803

7. Mori K, Shimada J, Kurisaka M, et al. (1995) Classification of hydrocephalus and outcome of treatment. Brain Dev 17:338-348

8. Mori K (1990) Hydrocephalus-revision of its definition and classification with special reference to "intractable infantile hydrocephalus". Childs Nerv Syst 6:198-204

9. Mori K (1995) Current concept of hydrocephalus: evolution of new classifications. Childs Nerv Syst 11:523-531 discussion p 531-522

10. Haverkamp F, Wolfle J, Aretz M, et al. (1999) Congenital hydrocephalus internus and aqueduct stenosis: aetiology and implications for genetic counselling. Eur J Pediatr 158:474-478

11. Chahlavi A, El-Babaa SK, Luciano MG (2001) Adult-onset hydrocephalus. Neurosurg Clin N Am 12:753-760, ix

12. Czosnyka M., Richards HK, Czosnyka Z, et al. (2004) Normal-pressure hydrocephalus. J Neurosurg 101:1083-1084 author reply 1084
13. Adams C, Johnston WP, Nevin NC (1982) Family study of congenital hydrocephalus. Dev Med Child Neurol 24:493-498

14. Fernell E, Hagberg B, Hagberg G, et al. (1986) Epidemiology of infantile hydrocephalus in Sweden. I. Birth prevalence and general data. Acta Paediatr Scand 75:975-981

15. Teebi AS, Naguib KK (1988) Autosomal recessive nonsyndromal hydrocephalus. Am J Med Genet 31:467-470

16. Partington MD (2001) Congenital hydrocephalus. Neurosurg Clin N Am 12:737-742, ix

17. Shannon MW, Nadler HL (1968) X-linked hydrocephalus. J Med Genet 5:326-328

18. Kuzniecky RI, Watters GV, Watters L, et al. (1986) X-linked hydrocephalus. Can J Neurol Sci 13:344-346

19. Jansen J (1975) Sex-linked hydrocephalus. Dev Med Child Neurol 17:633-640

20. Halliday J, Chow CW, Wallace D, et al. (1986) X linked hydrocephalus: a survey of a 20 year period in Victoria, Australia. J Med Genet 23:23-31

21. Sakata-Haga H, Sawada K, Ohnishi T, et al. (2004) Hydrocephalus following prenatal exposure to ethanol. Acta Neuropathol (Berl) 108:393-398

22. Castro-Gago M, Novo I, Pena J (1987) Maternal alcohol ingestion and neural tube defects: observation of four brothers in a family. Brain Dev 9:321322

23. Schinazi RF, Yao X (1995) Hydrocephalus induction in mice infected with herpes simplex virus type 2 after antiviral treatment. Antiviral Res 28:291-302

24. Stahl W, Kaneda Y (1997) Pathogenesis of murine toxoplasmic hydrocephalus. Parasitology 114( Pt 3): 219-229

25. Tsunoda I, McCright IJ, Kuang LQ, et al. (1997) Hydrocephalus in mice infected with a Theiler's murine encephalomyelitis virus variant. J Neuropathol Exp Neurol 56:13021313
26. Aolad HM, Inouye M, Hayasaka S, et al. (1998) Congenital hydrocephalus caused by exposure to low level $\mathrm{X}$-radiation at early gestational stage in mice. Biol Sci Space 12:256-257

27. Aolad HM, Inouye M, Darmanto W, et al. (2000) Hydrocephalus in mice following X-irradiation at early gestational stage: possibly due to persistent deceleration of cell proliferation. J Radiat Res (Tokyo) 41:213-226

28. Bay C, Kerzin L, Hall BD (1979) Recurrence risk in hydrocephalus. Birth Defects Orig Artic Ser 15:95-105

29. Burton BK (1979A) Empiric recurrence risks for congenital hydrocephalus. Birth Defects Orig Artic Ser 15:107-115

30. Burton BK (1979B) Recurrence risks for congenital hydrocephalus. Clin Genet 16:47-53

31. Barros-Nunes P, Rivas F (1993) Autosomal recessive congenital stenosis of aqueduct of Sylvius. Genet Couns 4:19-23

32. Chow CW, McKelvie PA, Anderson RM, et al. (1990) Autosomal recessive hydrocephalus with third ventricle obstruction. Am J Med Genet 35:310313

33. Abdul-Karim R, Iliya F, Iskandar G (1964) Consecutive Hydrocephalus: Report of 2 Cases. Obstet Gynecol 24:376-378

34. Game K, Friedman JM, Paradice B, et al. (1989) Fetal growth retardation, hydrocephalus, hypoplastic multilobed lungs, and other anomalies in 4 sibs. Am J Med Genet 33:276-279

35. Zlotogora J, Sagi M, Cohen T (1994) Familial hydrocephalus of prenatal onset. Am J Med Genet 49:202-204

36. Zlotogora J (1997) Autosomal recessive diseases among Palestinian Arabs. J Med Genet 34:765-766

37. Zlotogora J (1997) Genetic disorders among Palestinian Arabs. 2. Hydrocephalus and neural tube defects. Am J Med Genet 71:33-35

38. Castro-Gago M, Alonso A, Eiris-Punal J (1996) Autosomal recessive hydrocephalus with aqueductal stenosis. Childs Nerv Syst 12:188-191 
39. Chudley AE, McCullough C, McCullough DW (1997) Bilateral sensorineural deafness and hydrocephalus due to foramen of Monro obstruction in sibs: a newly described autosomal recessive disorder. Am J Med Genet 68:350-356

40. Moog U, Bleeker-Wagemakers EM, Crobach P, et al. (1998) Sibs with Axenfeld-Rieger anomaly, hydrocephalus, and leptomeningeal calcifications: a new autosomal recessive syndrome? Am J Med Genet 78:263266

41. Chalmers RM, Andreae L, Wood NW, et al. (1999) Familial hydrocephalus. J Neurol Neurosurg Psychiatry 67:410411

42. Hamada $H$, Watanabe $H$, Sugimoto M, et al. (1999) Autosomal recessive hydrocephalus due to congenital stenosis of the aqueduct of sylvius. Prenat Diagn 19:1067-1069

43. Castro-Gago M, Pintos-Martinez E, Forteza-Vila J, et al. (2001) Congenital hydranencephalic-hydrocephalic syndrome with proliferative vasculopathy: a possible relation with mitochondrial dysfunction. J Child Neurol 16:858-862

44. Verhagen WI, Bartels RH, Fransen E, et al. (1998) Familial congenital hydrocephalus and aqueduct stenosis with probably autosomal dominant inheritance and variable expression. J Neurol Sci 158:101-105

45. Vincent C, Kalatzis V, Compain S, et al. (1994) A proposed new contiguous gene syndrome on $8 \mathrm{q}$ consists of Branchio-Oto-Renal (BOR) syndrome, Duane syndrome, a dominant form of hydrocephalus and trapeze aplasia; implications for the mapping of the BOR gene. Hum Mol Genet 3:1859-1866

46. Jouet M, Rosenthal A, MacFarlane J, et al. (1993) A missense mutation confirms the L1 defect in X-linked hydrocephalus (HSAS). Nat Genet 4:331

47. Owler BK, Pickard JD (2001) Normal pressure hydrocephalus and cerebral blood flow: a review. Acta Neurol Scand 104:325-342

48. Edwards RJ, Dombrowski SM, Luciano MG, et al. (2004) Chronic hydrocephalus in adults. Brain Pathol 14:325-336

49. Katsuragi S, Teraoka K, Ikegami K, et al. (2000) Late onset X-linked hydrocephalus with normal cerebrospinal fluid pressure. Psychiatry Clin Neurosci 54:487-492

50. Portenoy RK, Berger A, Gross E (1984) Familial occurrence of idiopathic normal-pressure hydrocephalus. Arch Neurol 41:335-337
51. Robertson JM, Samankova L, Ingalls TH. (1966) Hydrocephalus and cleft palate in an inbred rabbit colony. J Hered 57:142-148

52. Mori A (1968) [Hereditary hydrocephalus in C57BL mouse]. No To Shinkei 20:695-700

53. Silson M, Robinson R (1969) Hereditary hydrocephalus in the cat. Vet Rec $84: 477$

54. Taraszewska A, Zaleska-Rutczynska Z (1970) Congenital hydrocephalus in mice of strains BN and C57BL. Pol Med J 9:187-195

55. Yoon CH, Slaney J (1972) Hydrocephalus: a new mutation in the Syrian golden hamster. J Hered 63:344-346

56. Yoon CH, Peterson JS (1977) Linkage group II in the Syrian hamster. Linkage between hydrocephalus and cream coat color. J Hered 68:418

57. Leipold HW, Schalles R (1977) Genetic defects in cattle: transmission and control. Vet Med Small Anim Clin 72:80-85

58. Park AW, Nowosielski-Slepowron BJ (1979) Hydrocephalus in the laboratory rat. Acta Morphol Neerl Scand 17:191-207

59. Kohn DF, Chinookoswong N, Chou SM (1984) Animal model of human disease. Congenital hydrocephalus. Am J Pathol 114:184-185

60. Weller RO, Williams BN (1975) Cerebral biopsy and assessment of brain damage in hydrocephalus. Arch Dis Child 50:763-768

61. Bruni JE, Del Bigio MR, Cardoso ER, et al. (1988) Hereditary hydrocephalus in laboratory animals and humans. Exp Pathol 35:239-246

62. Jones HC (1984) The development of congenital hydrocephalus in the mouse. Z Kinderchir 39 Suppl 2:87-88

63. Jones HC, Bucknall RM (1988) Inherited prenatal hydrocephalus in the H-Tx rat: a morphological study. Neuropathol Appl Neurobiol 14:263274

64. Oi S, Yamada H, Sato O, et al. (1996) Experimental models of congenital hydrocephalus and comparable clinical problems in the fetal and neonatal periods. Childs Nerv Syst 12:292-302

65. Jones HC, Carter BJ, Depelteau JS, et al. (2001) Chromosomal linkage associated with disease severity in the hydrocephalic H-Tx rat. Behav Genet 31:101-111

66. Jones HC, Depelteau JS, Carter BJ, et al. (2001) Genome-wide linkage analysis of inherited hydrocephalus in the H-Tx rat. Mamm Genome 12:2226
67. Jones HC, Depelteau JS, Carter BJ, et al. (2002) The frequency of inherited hydrocephalus is influenced by intrauterine factors in $\mathrm{H}-\mathrm{Tx}$ rats. Exp Neurol 176:213-220

68. Jones HC, Yehia B, Chen GF, et al. (2004) Genetic analysis of inherited hydrocephalus in a rat model. Exp Neurol 190:79-90

69. Cai X, McGraw G, Pattisapu JV, et al. (2000) Hydrocephalus in the H-Tx rat: a monogenic disease? Exp Neurol 163:131-135

70. Sasaki S, Goto H, Nagano H, et al. (1983) Congenital hydrocephalus revealed in the inbred rat, LEW/Jms. Neurosurgery 13:548-554

71. Jones HC, Carter BJ, Morel L (2003) Characteristics of hydrocephalus expression in the LEW/Jms rat strain with inherited disease. Childs Nerv Syst 19:11-18

72. Zygourakis CC, Rosen GD (2003) Quantitative trait loci modulate ventricular size in the mouse brain. J Neurol 461:362-369

73. Clark F (1932) Hydrocephalus, a hereditary character in the house mouse. Proc Natl Acad Sci USA 18:654-656

74. Clark F (1934) Anatomical basis of a hereditary hydrocephalus in the house mouse. Anat Rec 58:225-233

75. Zimmermann K (1933) Eine neue Mutation der Hausmaus: "hydrocephalus". Z Indukt Abstamm Vererbungsl 64:176-180

76. Clark F (1935) Two hereditary types of hydrocephalus in the house mouse (Mus musculus). Proc Natl Acad Sci USA 21(3): 150-152

77. Dickie M (1968) Obstructive hydrocephalus. Mouse News Lett 39:27

78. Borit A, Sidman RL (1972) New mutant mouse with communicating hydrocephalus and secondary aqueductal stenosis. Acta Neuropathol (Berl) 21:316-331

79. Gruneberg H (1943) Two new mutant genes in the house mouse. J Genet $45: 22-28$

80. Raimondi AJ, Bailey OT, McLone DG, et al. (1973) The pathophysiology and morphology of murine hydrocephalus in $\mathrm{Hy}-3$ and Ch mutants. Surg Neurol 1:50-55

81. Robinson ML, Allen CE, Davy BE, et al. (2002) Genetic mapping of an insertional hydrocephalus-inducing mutation allelic to hy3. Mamm Genome 13:625-632

82. Davy BE, Robinson ML (2003) Congenital hydrocephalus in hy3 mice is caused by a frameshift mutation in Hydin, a large novel gene. Hum Mol Genet 12:1163-1170 
83. Blackshear PJ, Graves JP, Stumpo DJ, et al. (2003) Graded phenotypic response to partial and complete deficiency of a brain-specific transcript variant of the winged helix transcription factor RFX4. Development 130:4539-4552

84. Kume T, Deng KY, Winfrey V, et al. (1998) The forkhead/winged helix gene Mf1 is disrupted in the pleiotropic mouse mutation congenital hydrocephalus. Cell 93:985-996

85. Hong HK, Lass JH, Chakravarti A (1999) Pleiotropic skeletal and ocular phenotypes of the mouse mutation congenital hydrocephalus (ch/Mf1) arise from a winged helix/forkhead transcription factor gene. Hum Mol Genet 8:625-637

86. Descipio C, Schneider L, Young TL, et al. (2005) Subtelomeric deletions of chromosome 6p: molecular and cytogenetic characterization of three new cases with phenotypic overlap with Ritscher-Schinzel (3C) syndrome. Am J Med Genet A 134:3-11

87. Hong HK, Chakravarti A, Takahashi JS (2004) The gene for soluble $\mathrm{N}$-ethylmaleimide sensitive factor attachment protein alpha is mutated in hydrocephaly with hop gait (hyh) mice. Proc Natl Acad Sci USA 101:1748-1753

88. Kuwamura M, Kinoshita A, Okumoto $\mathrm{M}$, et al. (2004) Hemorrhagic hydrocephalus (hhy): a novel mutation on mouse chromosome 12 . Brain Res Dev Brain Res 152:69-72

89. Abdelilah S, Mountcastle-Shah E, Harvey M, et al. (1996) Mutations affecting neural survival in the zebrafish Danio rerio. Development 123:217-227

90. Driever W, Solnica-Krezel L, Schier AF, et al. (1996) A genetic screen for mutations affecting embryogenesis in zebrafish. Development 123:37-46

91. Sheen VL, Basel-Vanagaite L, Goodman JR, et al. (2004) Etiological heterogeneity of familial periventricular heterotopia and hydrocephalus. Brain Dev 26:326-334

92. Miyan JA, Khan MI, Kawarada Y, et al. (1998) Cell death in the brain of the HTx rat. Eur J Pediatr Surg 8 Suppl 1:43-48

93. Mori F, Tanji K, Yoshida Y, et al. (2002) Thalamic retrograde degeneration in the congenitally hydrocephalic rat is attributable to apoptotic cell death. Neuropathology 22:186193

94. Draper CE, Owen-Lynch PJ, Bannister CM, et al. (2001) Proliferation of cerebral cortical cells from the hydrocephalic HTx rat: an in vitro study. Eur J Pediatr Surg 11 Suppl 1:S51-52
95. Mashayekhi F, Bannister CM, Miyan JA (2001) Failure in cell proliferation in the germinal epithelium of the HTx rats. Eur J Pediatr Surg 11 Suppl $1:$ S57-59

96. Somera KC, Jones HC (2004) Reduced subcommissural organ glycoprotein immunoreactivity precedes aqueduct closure and ventricular dilatation in $\mathrm{H}-\mathrm{Tx}$ rat hydrocephalus. Cell Tissue Res 315:361-373

97. Somera KC, Jones H (2002) Subcommissural organ dysfunction in $\mathrm{H}-\mathrm{Tx}$ rats with early-onset hydrocephalus. Eur J Pediatr Surg 12 Suppl 1:S45-47

98. Ulfig N, Bohl J, Neudorfer F, et al. (2004) Brain macrophages and microglia in human fetal hydrocephalus. Brain Dev 26:307-315

99. Okamoto N, Del Maestro R, Valero R, et al. (2004) Hydrocephalus and Hirschsprung's disease with a mutation of L1CAM. J Hum Genet 49:334-337

100. Chae TH, Kim S, Marz KE, et al. (2004) The hyh mutation uncovers roles for alpha Snap in apical protein localization and control of neural cell fate. Nat Genet 36:264-270

101. Kondziella D, Qu H, Ludemann W, et al. (2003) Astrocyte metabolism is disturbed in the early development of experimental hydrocephalus. J Neurochem 85:274-281

102. Takano T, Mekata Y, Yamano T, et al. (1993) Early ependymal changes in experimental hydrocephalus after mumps virus inoculation in hamsters. Acta Neuropathol (Berl) 85:521-525

103. Takano T, Rutka JT, Becker LE (1996) Overexpression of nestin and vimentin in ependymal cells in hydrocephalus. Acta Neuropathol (Berl) 92:9097

104. Jimenez AJ, Tome M, Paez P, et al. (2001) A programmed ependymal denudation precedes congenital hydrocephalus in the hyh mutant mouse. J Neuropathol Exp Neurol 60:1105-1119

105. Wagner C, Batiz LF, Rodriguez S, et al. (2003) Cellular mechanisms involved in the stenosis and obliteration of the cerebral aqueduct of hyh mutant mice developing congenital hydrocephalus. J Neuropathol Exp Neurol 62:1019-1040

106. Ibanez-Tallon I, Pagenstecher A, Fliegauf M, et al. (2004) Dysfunction of axonemal dynein heavy chain Mdnah5 inhibits ependymal flow and reveals a novel mechanism for hydrocephalus formation. Hum Mol Genet 13:2133-2141
107. Fernandez-Llebrez P, Grondona JM, Perez J, et al. (2004) Msx1-deficient mice fail to form prosomere 1 derivatives, subcommissural organ, and posterior commissure and develop hydrocephalus. J Neuropathol Exp Neurol 63:574-586

108. Ramos C, Fernandez-Llebrez P, Bach A, et al. (2004) Msxl disruption leads to diencephalon defects and hydrocephalus. Dev Dyn 230:446-460

109. Fukumitsu H, Ohmiya M, Nitta A, et al. (2000) Aberrant expression of neurotrophic factors in the ventricular progenitor cells of infant congenitally hydrocephalic rats. Childs Nerv Syst 16:516-521

110. Ohmiya M, Fukumitsu H, Nitta A, et al. (2001) Administration of FGF-2 to embryonic mouse brain induces hydrocephalic brain morphology and aberrant differentiation of neurons in the postnatal cerebral cortex. J Neurosci Res 65:228-235

111. Miyan JA, Mashayekhi F, Bannister CM (2001) Developmental abnormalities in early-onset hydrocephalus: clues to signalling. Symp Soc Exp Biol 91-106

112. Galbreath E, Kim SJ, Park K, et al. (1995) Overexpression of TGF-beta 1 in the central nervous system of transgenic mice results in hydrocephalus. J Neuropathol Exp Neurol 54:339-349

113. Cohen AR, Leifer DW, Zechel M, et al. (1999) Characterization of a model of hydrocephalus in transgenic mice. J Neurosurg 91:978-988

114. Li X, Miyajima M, Arai H (2005) Analysis of TGF-beta2 and TGF-beta3 expression in the hydrocephalic $\mathrm{H}-\mathrm{Tx}$ rat brain. Childs Nerv Syst 21:32-38

115. Doublier S, Duyckaerts C, Seurin D, et al. (2000) Impaired brain development and hydrocephalus in a line of transgenic mice with liver-specific expression of human insulin-like growth factor binding protein-1. Growth Horm IGF Res 10:267-274

116. Nitta J, Tada T (1998) Ultramicroscopic structures of the leptomeninx of mice with communicating hydrocephalus induced by human recombinant transforming growth factor-beta 1. Neurol Med Chir (Tokyo) 38:819-824 discussion 824-815

117. Johanson CE, Szmydynger-Chodobska J, Chodobski A, et al. (1999) Altered formation and bulk absorption of cerebrospinal fluid in FGF-2-induced hydrocephalus. Am J Physiol 277:R263-271

118. Krebs DL, Metcalf D, Merson TD, et al. (2004) Development of hydrocephalus in mice lacking SOCS7. Proc Natl Acad Sci USA 101:15446-15451 
119. Zechel J, Gohil H, Lust WD, et al. (2002) Alterations in matrix metalloproteinase-9 levels and tissue inhibitor of matrix metalloproteinases-1 expression in a transforming growth factor-beta transgenic model of hydrocephalus. J Neurosci Res 69:662-668
120. Crews L, Wyss-Coray T, Masliah E (2004) Insights into the pathogenesis of hydrocephalus from transgenic and experimental animal models. Brain Pathol 14:312-316

121. Tullio AN, Bridgman PC, Tresser NJ, et al. (2001) Structural abnormalities develop in the brain after ablation of the gene encoding nonmuscle myosin II-B heavy chain. J Comp Neurol 433:62-74
122. Makiyama $\mathrm{Y}$, Shoji $\mathrm{S}$, Mizusawa $\mathrm{H}$ (1997) Hydrocephalus in the Otx2+/mutant mouse. Exp Neurol 148:215221

123. Jones HC, Harris NG, Rocca JR, Anderson RW (2000) Progressive tissue injury in infantile hydrocephalus and prevention/reversal with shunt treatment. Neurol Res 22:89-96 